\title{
Ultrasound-guided quadratus Iumborum block verses transversus abdominis plane block for post-operative analgesia in patients undergoing total abdominal hysterectomy: A prospective observational study
}

\author{
Mohamad Sadiq Malla', Sameena Ashraf ${ }^{2}$, Rayees Najib ${ }^{3}$, Abdul Hakeem ${ }^{4}$ \\ ${ }^{1}$ Associate Professor, ${ }^{4}$ Professor, Department of Anesthesiology and Critical Care, Government Medical College, \\ Srinagar, ${ }^{2}$ Assistant Professor (Deputed), Department of Gynecology and Obstetrics, Government Medical College, \\ Baramulla, ${ }^{3}$ Assistant Professor Department of Anesthesiology and Critical Care, Government Medical College, \\ Jammu, Jammu and Kashmir, India
}

Background: Total abdominal hysterectomy (TAH) is a major surgical procedure associated with significant post-operative pain and discomfort. Ultrasound-guided (USG) quadratus lumborum (QL) and transversus abdominis plane (TAP) block are regional analgesic techniques that have role in post-operative pain management after TAH. Aims and Objectives: This study aims to compare quality of post-operative analgesia and analgesic consumption in USG-guided QL block and TAP block in patients undergoing TAH under spinal anesthesia. Materials and Methods: Hundred patients scheduled for TAH were observed over a period of 2 years. The patients who had received either TAP block or QL block were assigned in two groups. Patients who received TAP block after spinal anesthesia were labeled as Group A and patients who received QL block after spinal anesthesia were labeled as Group B. Postoperatively, VAS score, rescue analgesia, analgesic consumption, and hemodynamic parameters were observed at 0, 1, 3 6, 9, 12, 18, 24, and $48 \mathrm{~h}$. Statistical Analysis: Student's independent t-test was employed for comparing continuous variables. Chi-square test or Fisher's exact test, whichever appropriate, was applied for comparing categorical variables. $P<0.05$ was considered statistically significant. Results: Time for rescue analgesic requirement was higher in the Group $B$ than the Group A (mean $\pm S D: 16.5 \pm 3.096 \mathrm{~h}$ vs. $8.5 \pm 1.998$ h) $(P<0.001)$. Group $B$ had significantly less analgesic demand $(P<0.001)$ at 12,24 , and 48 h postoperatively. The VAS at rest and movement was significantly reduced in Group B at all times. Hemodynamic parameters and post-operative side effects between two groups remained insignificant. Conclusion: USG-guided quadratus lumber block provided prolonged analgesia as compared to TAP block in patients undergoing TAH after spinal anesthesia. USG-guided quadratus lumber block provides better multimodal post-operative analgesia relief in patients.

Key words: Quadratus lumborum blocks; Total abdominal hysterectomy; Transversus abdominis bock

\section{Access this article online}

Website:

http://nepjol.info/index.php/AJMS DOI: 10.3126/ajms.v12i11.39202

E-ISSN: 2091-0576

P-ISSN: 2467-9100

Copyright (c) 2021 Asian Journal of Medical Sciences

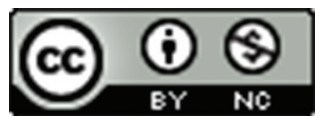

This work is licensed under a Creative Commons Attribution-NonCommercial 4.0 International License.

\section{INTRODUCTION}

Total abdominal hysterectomy (TAH) is a major surgical procedure after which significant post-operative pain and discomfort are anticipated. ${ }^{1}$ The abdominal wall incision is the main cause of pain experienced by the patients undergoing abdominal surgeries. ${ }^{2}$ Hence, blocking the sensory innervations to the abdominal wall

Address for Correspondence:

Dr. Sameena Ashraf, Assistant Professor (Deputed), Department of Gynecology and Obstetrics, Government Medical College, Baramulla, Jammu and Kashmir, India. Mobile: 7006683174. E-mail: saminadrgmc@gmail.com 
is promising mode of providing post-operative analgesia after abdominal wall incision. ${ }^{3}$ Post-operative analgesia is also important to avoid various complications such as venous thromboembolism, respiratory complications, and prolonged hospital stay. ${ }^{4} \mathrm{~A}$ multimodal post-operative pain management regimen providing superior grade analgesia with negligible adverse effects is required to control severe pain after TAH. For systemic administration, opioids are the analgesic of choice but they have many adverse effects such as sedation, nausea and vomiting, urinary retention, delayed recovery, and post-operative ileus. ${ }^{5}$ Hence, different methods are required to control pain and reduce opioid consumption and its adverse effects.

The trend of utilizing peripheral nerve blocks as part of multimodal analgesia regime has increased in the past two decades. ${ }^{6-8}$ Abdominal field blocks have been followed for many years and extensively used for pain management following abdominal surgeries such as laparotomies and appendicectomies. ${ }^{910}$ Introduced by Rafi in anesthetic practice in 2001, transversus abdominis plane (TAP) block is a widely practiced peripheral nerve block utilized to anesthetize the somatic nerves supplying the anterior abdominal wall by depositing local anesthetic in the neuromuscular plane between internal oblique and transversus abdominis muscle layer. ${ }^{11}$ Blanco was the first who described quadratus lumborum $(\mathrm{QL})$ block. ${ }^{12}$ Somatic pain after upper and lower abdominal surgery can be controlled by QL block. ${ }^{13}$ QL block is considered to be an easy technique to learn as it is easy to get the key sonoanatomic markers for QL block. QL block produces effective post-operative analgesia after abdominal surgery, laparoscopic surgery, anterior abdominal wall surgery, and hip and femur surgery. The analgesic effect of QL block covers 24-48 h.

\section{Aims and objectives}

The aim of our study was to compare the ultrasound-guided TAP block with QL block for post-operative analgesia in patients undergoing TAH under spinal anesthesia.

\section{MATERIALS AND METHODS}

This prospective observational study "Ultrasound-guided QL block and TAP block for post-operative analgesia after TAH under spinal anesthesia" was conducted at Lal Ded Hospital, an Associated Hospital of Government Medical College, Srinagar.

\section{Study population}

After approval from ethical committee of the institution, we observed 100 patients over a period of 20 months who had received either TAP block or QL block.

Written informed consent was obtained in all patients.
Inclusion criteria

Hundred patients belonging to ASA Class I and II planned for abdominal hysterectomy under spinal anesthesia were included in the study.

\section{Exclusion criteria}

The following criteria were excluded from the study:

1. Patients with coagulopathy.

2. Patients belonging to ASA Class $>$ II.

3. Patients with body mass index $>30$.

4. Patient with known hypersensitivity to local anesthetic.

5. Patients with anatomical abnormality of spine.

\section{Pre-anesthetic evaluation}

The patients enrolled in the study were clinically assessed, evaluated, and investigated as per the normal hospital protocol and pro forma. The visual analog scale (VAS) as the method of rating pain was explained to all the patients before the surgery.

On arrival to operating room, consent was checked and fasting status confirmed. Standard monitoring including ECG, blood pressure, and pulse oximeter was instituted. Intravenous access using $18 \mathrm{G}$ intravenous cannula was established.

In all patients, spinal anesthesia was performed. With the patient in the sitting position, the midline and level of L3-4 and L4-5 intervertebral spaces were identified. Using 26 G Quincke's spinal needle, hyperbaric bupivacaine $15 \mathrm{mg}$ was injected intrathecally. The patient was immediately placed in the supine position. Spinal anesthesia was considered successful when a bilateral block to T6 assesses by loss of cold and touch (blunt pin) discrimination was established five min after the spinal injection.

Anesthetic and surgical treatments were performed in usual manner.

At the end of the surgery, with the patient in supine position, still fully monitored and after the abdomen was cleaned with 10\% betadine solution and under all aseptic precautions, the TAP and QL blocks were performed by an experienced anesthesiologist.

For statistical purposes, the patients who had received either TAP block or QL block were randomly categorized in two groups. The patients who had received TAP block were assigned Group A and the patients who had received QL block were assigned Group B.

Group A: This group consisted of the patients who had received ultrasound-guided TAP block with $20 \mathrm{ml}$ of $0.2 \%$ ropivacaine. Group B: This group consisted of the patients 
who had received ultrasound-guided QL block with $20 \mathrm{ml}$ of $0.2 \%$ ropivacaine.

Average time required for the procedures (QL block vs. TAP block) were not analyzed statistically. There was no adverse effect of the procedure in any patient.

\section{Post-operative assessment}

Immediately after the performance of block, all the patients were observed for $1 \mathrm{~h}$ to ensure cardiorespiratory stability. Serial measurements of heart rate, blood pressure, and respiratory rate were taken at every $5 \mathrm{~min}$ for the first $30 \mathrm{~min}$ and then every $10 \mathrm{~min}$ until $1 \mathrm{~h}$ post-procedure. At the completion of surgery, no analgesia other than the two blocks in respective groups was given. The pressure and severity of pain were assessed systematically using VAS at $0,1,2,4,8,12,18,24,36$, and $48 \mathrm{~h}$. Time to first rescue analgesia, total analgesia consumption, and post-operative nausea/vomiting were also observed. Rescue analgesia was given when VAS $>4$. Injection paracetamol $1 \mathrm{~g}$ was used as rescue analgesia.

\section{Statistical analysis}

Sample size was calculated by taking the previous data by Blanco et al., ${ }^{14}$ into consideration. The required sample size was 100 patients with power more than $80 \%$ and alpha error of $0.05 \%$. The recorded data were compiled and entered into a spreadsheet (Microsoft Excel) and then exported to data editor of SPSS Version 20.0 (SPSS Inc., Chicago, Illinois, USA). Continuous variables were expressed as mean $\pm \mathrm{SD}$ and categorical variables were summarized as frequencies and percentages. Graphically, the data were presented by bar diagrams and line diagrams. Student's independent t-test was employed for comparing continuous variables. Chi-square test or Fisher's exact test, whichever appropriate, was applied for comparing categorical variables. $\mathrm{P}<0.05$ was considered statistically significant. All P-values were two tailed.

\section{RESULTS}

Our study group comprised of 100 patients, with 54 patients in Group A who had received ultrasound-guided TAP block with $20 \mathrm{ml}$ of $0.2 \%$ ropivacaine and 46 patients in Group B who had received ultrasound-guided QL block with $20 \mathrm{ml}$ of $0.2 \%$ ropivacaine. Patient's demographics were similar with no significant differences between two groups in terms of age, weight, height, and duration of surgery (Table 1). At the same time, there were no statistically significant disparity in oxygen saturation level, heart rate, and mean blood pressure. The comparison of VAS pain score postoperatively at $0,1,3,6,9,18,24,36$, and $48 \mathrm{~h}$ showed significant difference $(\mathrm{P}<0.001)$. The overall VAS score in Group B was lower than in Group A, as depicted in Table 2 and Figure 1.

The duration of analgesia in Group A ranged from 6 to $12 \mathrm{~h}$ with a mean duration of $8.5 \pm 1.998 \mathrm{~h}$. In Group B, the duration ranged from 9 to $24 \mathrm{~h}$ with a mean duration of $16.5 \pm 3.096 \mathrm{~h}$. The difference in duration of analgesia between the two groups was statistically significant $(\mathrm{P}<0.001)$ (Figure 1 and Table 3).

The total rescue analgesia consumption between the two groups was compared at 12, 24, and 48 h. In Group A, the mean analgesic consumption dose was more than in Group B at all time intervals, as shown in Table 4 and Figure 2. The difference was statistically significant $(\mathrm{P}<0.001)$.

\begin{tabular}{|c|c|c|c|}
\hline Parameters & Group A, n=54 & Group B, n=46 & $P$ value \\
\hline Age (years) & $46.71 \pm 3.68$ & $47.07 \pm 3.77$ & 0.860 \\
\hline Height (cm) & $166.3 \pm 4.61$ & $168.4 \pm 5.54$ & 0.264 \\
\hline Weight (kg) & $64.8 \pm 4.31$ & $63.1 \pm 3.65$ & 0.072 \\
\hline $\begin{array}{l}\text { Duration } \\
\text { of surgery } \\
\text { (minutes) }\end{array}$ & $38.1 \pm 5.63$ & $36.9 \pm 6.45$ & 0.307 \\
\hline
\end{tabular}

Table 2: Post-operative VAS in two groups at
various intervals of time
\begin{tabular}{lccc} 
VAS time & Group A \\
intervals in hours & $(\mathbf{n = 5 4 )}$ & $\begin{array}{c}\text { Group B } \\
(\mathbf{n}=\mathbf{4 6})\end{array}$ & P value \\
\hline 0 & $0.52 \pm 0.540$ & $0.39 \pm 0.493$ & 0.225 \\
1 & $1.13 \pm 0.646$ & $0.63 \pm 0.488$ & $<0.001^{*}$ \\
3 & $2.13 \pm 0.646$ & $0.91 \pm 0.590$ & $<0.001^{*}$ \\
6 & $3.26 \pm 1.102$ & $1.43 \pm 0.583$ & $<0.001^{*}$ \\
9 & $4.02 \pm 1.677$ & $2.30 \pm 0.726$ & $<0.001^{*}$ \\
12 & $3.46 \pm 1.463$ & $2.39 \pm 1.064$ & $<0.001^{*}$ \\
18 & $3.22 \pm 1.205$ & $3.17 \pm 1.981$ & 0.514 \\
24 & $3.91 \pm 1.457$ & $2.52 \pm 1.786$ & $<0.001^{*}$ \\
36 & $2.76 \pm 1.822$ & $1.72 \pm 1.905$ & $0.006^{*}$ \\
48 & $1.15 \pm 1.053$ & $0.78 \pm 0.664$ & $0.045^{*}$ \\
\hline *Significant difference between groups P<0.05. VAS: Visual analog scale
\end{tabular}

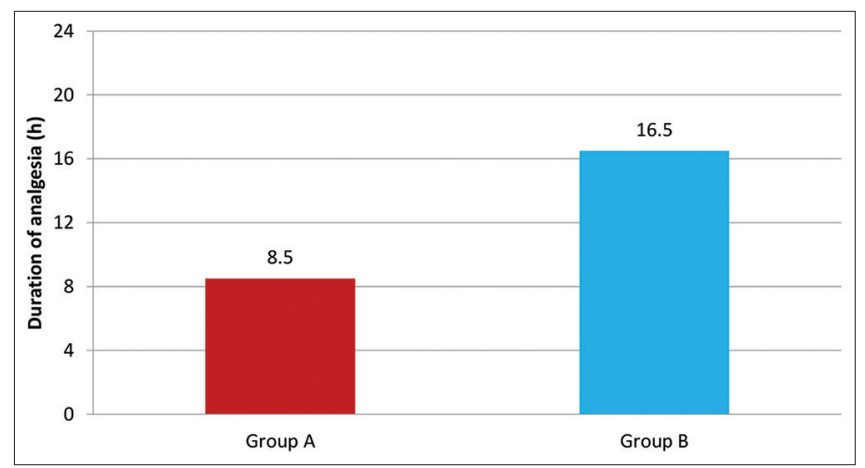

Figure 1: Duration of analgesia (hours) in two groups 


\begin{tabular}{|c|c|c|c|}
\hline \multirow[t]{2}{*}{ Groups } & \multicolumn{2}{|c|}{ Duration of analgesia in hours } & \multirow[t]{2}{*}{$P$ value } \\
\hline & Mean $\pm S D$ & Range & \\
\hline $\begin{array}{l}\text { Group A }(n=54) \\
\text { Group B }(n=460\end{array}$ & $\begin{array}{c}8.5 \pm 1.998 \\
16.5 \pm 3.096\end{array}$ & $\begin{array}{l}6-12 \\
9-24\end{array}$ & $<0.001^{*}$ \\
\hline
\end{tabular}

*Significant difference between groups $\mathrm{P}<0.05$

Table 4: Analgesic consumption (in grams) in two groups at various time intervals

\begin{tabular}{lccc}
\hline Time interval & $\begin{array}{c}\text { Group A } \\
(\mathbf{n = 5 4 )}\end{array}$ & $\begin{array}{c}\text { Group B } \\
(\mathbf{n = 4 6 )}\end{array}$ & P value \\
\hline $12 \mathrm{~h}$ & $1.07 \pm 0.26$ & $0.43 \pm 0.67$ & $<0.001^{*}$ \\
$24 \mathrm{~h}$ & $2.11 \pm 0.32$ & $1.35 \pm 0.67$ & $<0.001^{*}$ \\
$48 \mathrm{~h}$ & $2.67 \pm 0.67$ & $1.65 \pm 0.60$ & $<0.001^{*}$ \\
\hline *Significant difference between groups $\mathrm{P}<0.05$ & &
\end{tabular}

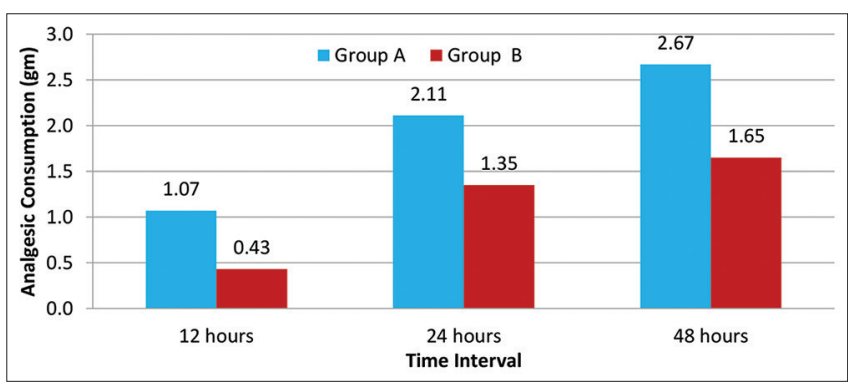

Figure 2: Analgesic consumption (in grams) in two groups at various time intervals

\section{DISCUSSION}

Relief from pain is part of the fundamental human right to health. ${ }^{15}$ Pain relief after TAH varies from a single suppository to high tech invasive analgesia techniques for $48 \mathrm{~h}$. In patients with abdominal surgery, multimodal analgesic technique reduces morbidity, costs, and hospital stay. ${ }^{16}$ Abdominal wall incision is the major origin of pain experienced by patients after abdominal surgery. ${ }^{17}$ Although systematically administered opiates and central neuraxial techniques remain mainstay analgesic modality after abdominal surgery, they cause considerable adverse effects.

Since the widespread introduction of ultrasound for assisting techniques used in anesthetic theaters, peripheral nerve blocks of the trunk have been used more frequently to produce analgesia and anesthesia for surgeries involving the thorax, abdomen, and lower extremities.

Compared to traditional techniques, ultrasound-guided peripheral nerve block procedures enable anesthesiologists to reliably inject local anesthetic at a target location with a decreased risk of needle trauma to the nerve and surrounding structures.
The present study compared the ultrasound-guided TAP block and QL block after TAH under spinal anesthesia with regard to their duration of analgesia, quality of analgesia, hemodynamic parameters, total dose of analgesia consumption, and complications.

In our study, the mean duration of analgesia for US-guided TAP block was $8.5 \mathrm{~h}(6-12 \mathrm{~h})$, and for QL block, it was $16.5 \mathrm{~h}(9-24 \mathrm{~h})$ with $\mathrm{P}<0.001$ which shows statistically significant difference.

Blanco et al., ${ }^{14}$ in a randomized controlled trial done in 2016, concluded that QL block produces more prolonged analgesia than TAP block. Similar results have been published in other studies and the major advantage of $\mathrm{QL}$ block was considered to be its analgesic action similar to opioid analgesics, yet avoiding the adverse effects such as nausea and vomiting.

The prolonged duration of action after QL block is suggested to be due to the spread of local anesthetic solution along the thoracolumbar fascia and endothoracic fascia to the paravertebral space.

It is said that QL block is the extension of TAP block toward the dorsal region. According to Hebbard et al., ${ }^{18}$ US-guided TAP block has the limitation of requiring two levels of block to cover incision above and below umbilicus. The advantages of single shot QL block is that it covers the dermatome segments from L3 to T4 segments as the drug is expected to travel from the quadrates lumborum to higher paravertebral space. Carney et al., ${ }^{19}$ described that the contrast solution placed posteriorly accumulates near the lateral border of the QL and then spreads in a posterior cranial fashion to the anterior aspect of QL and psoas major to lie at the paravertebral space.

Murouchi et al., ${ }^{20}$ investigated the relationship between the local anesthetics blood level and the efficacy of the QL block type 2 and TAP block in adults, and they found that in TAP block, the local anesthetic blood levels were higher than QL block type 2, but the analgesic effect was better with QL block type 2 than with TAP block, and this result was explained by the following, during QL block, some of the administered drugs thought to move from the intermuscular space into the paravertebral space which is filled with adipose tissue and the local tissue perfusion of the adipose tissue is low which results in low absorption speed of a local anesthetic into the blood.

In our study, pain was assessed using VAS. The VAS scores were significantly better at every observation time in the QL block group than in the TAP block group. Baidya et al., ${ }^{21}$ performed single injection QL transmuscular block 
between the QL and psoas major in lateral position on five children undergoing pyeloplasty, and they reported that it was associated with good post-operative analgesia. Oksuz et al., ${ }^{22}$ who compared TAP block and QL block in pediatric patients undergoing lower abdominal surgery and reported that TAP block group showed significantly higher postoperative FLACC scores than QL block group $(\mathrm{P}<0.05)$; furthermore, the number of patients who received rescue analgesia in the first $24 \mathrm{~h}$ postoperatively was significantly higher in TAP block group than in QL block group $(\mathrm{P}<0.05)$. Parent's satisfaction scores were lower in TAP block group than in QL block group.

In both the groups, heart rate, mean arterial pressures, and oxygen saturation were monitored postoperatively. There was no significant difference in the hemodynamic parameters in both the groups.

Rescue analgesia was provided if the VAS score was equal to or more than 4. Injection paracetamol $1 \mathrm{~g}$ intravenous infusion was used as rescue analgesia. In our study, the time to request for first rescue analgesia and the total consumption of rescue analgesia in $48 \mathrm{~h}$ were observed. Patients who received QL block had significantly less cumulative rescue analgesia doses than patients who received the TAP block $(\mathrm{P}<0.001)$ at all time intervals recorded. Youse $\mathrm{f}^{23}$ conducted a study in 2018 in which he compared TAP and QL blocks in women who underwent TAH. Fentanyl and morphine requirement were less in the QL block group. A meta-analysis published in 2016 compared eight trials studying the lateral technique of TAP block (the widely recognized TAP block in between internal oblique and transverses abdominis muscles) versus four trials studying the posterior technique for a TAP block (which is similar to QL block type 1) and reported that patients who had the posterior TAP block had less post-operative morphine consumption during 12-24 h and $24-48 \mathrm{~h}$ intervals.

In our study, none of the patients developed any complication in both the study groups. Kumar et al., ${ }^{24}$ compared TAP block versus QL block for post-operative analgesia following lower abdominal surgeries and concluded that the adverse events associated with escalating doses of morphine, such as pruritus, nausea, somnolence, and respiratory depression can also be avoided by lower doses required with QL block.

The topographically broader field of action (T6 to L1) and longer duration of pain relief make QL block superior to TAP block in providing post-operative pain relief. Although the duration of action differs with each study, there is a significant difference between TAP and QL blocks.

\section{CONCLUSION}

After reviewing the available literature and conducting the present study, it can be concluded that ultrasound-guided nerve blocks (TAP block and QL block) can be used as a part of multimodal analgesia for better post-operative pain relief in lower abdominal surgeries like TAH, especially when given before the resolution of spinal anesthesia. Further, it was observed that QL block was superior to TAP block in terms of better pain control (duration and quality) as shown by lower VAS score, demand for the first rescue analgesia which was delayed and total consumption of rescue analgesia was less in the first $48 \mathrm{~h}$. As QL block provides good quality analgesia for longer duration without side effects, but proper understanding of the sonoanatomy and technical aspects of QL block are essential for its effective and safe use.

\section{ACKNOWLEDGMENT}

The authors take this opportunity to thank the Department of Obstetrics and Gynaecology and Department of Anaesthesiology and Critical Care, Government Medical College, Srinagar, for their whole hearted support for this study.

\section{REFERENCES}

1. $\mathrm{Ng} \mathrm{A}$, Swami A, Smith G, Davidson AC and Emembolu J. The analgesic effects of intraperitoneal and incisional bupivacaine with epinephrine after total abdominal hysterectomy. Anesth Analg. 2002;95(1):158-162

https://doi.org/10.1097/00000539-200207000-00028

2. Wall PD and Melzack R. Pain measurements in persons in pain. In: Textbook of Pain. $4^{\text {th }}$ ed. Edinburgh, UK: Churchill Livingstone; 1999. p. 409-426.

3. Kuppuvelumani $P$, Jaradi $H$ and Delilkan $A$. Abdominal nerve blockade for postoperative analgesia after caesarean section. Asia Oceania J Obstet Gynaecol. 1999;19(2):165-169. https://doi.org/10.1111/j.1447-0756.1993.tb00368.x

4. Mankikar MG, Sardesai SP and Ghodki PS. Ultrasound-guided transversus abdominis plane block for postoperative analgesia in patients undergoing caesarean section. Indian J Anaesth. 2016;60(4):253-257.

https://doi.org/10.4103/0019-5049.179451

5. Shaaban M, Esa WA, Maheshwari K, Elsharkawy $\mathrm{H}$ and Soliman LM. Bilateral continuous quadratus lumborum block for acute abdominal pain as a rescue after opiod induced respiratory depression. AA Case Rep. 2015;5(7):107-111.

https://doi.org/10.1213/xaa.0000000000000188

6. McDonnell JG, O'Donnell B, Curley G, Hefferman A, Power C and Laffey JG. The analgesic efficacy of transversus abdominis plane block after abdominal surgery: A prospective randomised trial. Anesth Analg. 2007;104(1):193-197.

https://doi.org/10.1213/01.ane.0000250223.49963.0f

7. McDonnell JG, Carney J and Laffey JG. The transversus abdominis plane block provides effective postoperative 
analgesia in patient undergoing total abdominal hysterectomy. Anesth Analg. 2008;107(6):2056-2060.

https://doi.org/10.1213/ane.0b013e3181871313

8. Marhofer P, Harrop-Griffiths $W$ and Willschke $H$. Fifteen years of ultrasound guidance in regional anaesthesia: Part 2 recent developments in block techniques. $\mathrm{Br} \mathrm{J}$ Anaesth. 2010;104(6):673-683.

https://doi.org/10.1093/bja/aeq086

9. Muktar K. Transversus abdominis plane (TAP) block. J NYSORA. 2009;12:28-33.

10. Suresh S and Chan VW. Ultrasound guided transversus abdominis plane block in infants, children and adolescents: A simple procedural guidance for their performance. Paediatr Anaesth. 2009;19(4):296-299.

https://doi.org/10.1111/j.1460-9592.2009.02958.x

11. Rafi AN. Abdominal field block a new approach via lumbar triangle. Anaesthesia. 2001;56(10):1024-1026. https://doi.org/10.1046/j.1365-2044.2001.02279-40.x

12. Blanco R. TAP block under ultrasound guidance: The description of a non pops technique. Reg Anesth Pain Med. 2007;32(5):130.

https://doi.org/10.1016/j.rapm.2007.06.268

13. Kadam VR. Ultrasound-guided quadratus lumborum block as a postoperative analgesic technique for laparotomy. J Anaesthesiol Clin Pharmacol. 2013;29(4):550-552.

https://doi.org/10.4103/0970-9185.119148

14. Blanco R, Ansari T, Riad W and Shetty N. Quadratus lumborum block versus transversus abdominis plane block for postoperative pain after cesarean delivery a randomised controlled trial. Reg Anesth Pain Med. 2016;41(6):757-762.

https://doi.org/10.1097/01.aoa.0000521263.80265.f7

15. Brennan F, Carr DB and Cousins M. Pain management: A fundamental human right. Anesth Analg. 2007;105(1):205-221. https://doi.org/10.1213/01.ane.0000268145.52345.55

16. Jorgenson $\mathrm{H}$, Wetterslev J, Moiniche S and Dahl JB. Epidural local anesthetics vsopiod-based analgesic regimens on postoperative gastrointestinal paralysis, PONV and pain after abdominal surgery. Cochrane Database Syst Rev. 2000;4:CD001893. https://doi.org/10.1002/14651858.cd001893

17. Moore $\mathrm{K}$ and Anne M. In: Oxorn V and Marion EM, editors. Essential Clinical Anatomy. $3^{\text {rd }}$ ed. USA: Lippincott Williams and Wilkins; 2007. p. 666.

18. Hebbard P, Fujiwara $Y$, Shibata $Y$ and Royse C. Ultrasoundguided transversus abdominis plane (TAP) block. Anaesth Intens Care. 2007;35(4):616-617.

19. Carney J, Finnerty O, Rauf J, Bergin D, Laffey JG and McDonnell JG. Studies on the spread of local anaesthetic solution in transversus abdominis plane blocks. Anaesthesia. 2011;66(11):1023-1030. https://doi.org/10.1111/j.1365-2044.2011.06855.x

20. Murouchi T, Iwasaki S and Yamakage M. Quadratus lumborum block: Analgesic effects and chronological ropivacaine concentrations after laparoscopic surgery. Reg Anesth Pain Med. 2016;41(2):146-150. https://doi.org/10.1097/aap.0000000000000349

21. Baidya DK, Maitra S, Arora MK and Agarwal A. Quadratus lumborum block: An effective method of perioperative analgesia in children undergoing pyeloplasty. J Clin Anesth. 2015;27(8):694-696.

https://doi.org/10.1016/j.jclinane.2015.05.006

22. Oksuz G, Bilal B, Gürkan Y, Urfalioglu A, Arslan M, Gisi G, et al. Quadratus lumborum block versus transversus abdominis plane block in children undergoing low abdominal surgery: A randomized controlled trial. Reg Anesth Pain Med. 2017;42(5):674-679. https://doi.org/10.1097/aap.0000000000000645

23. Yousef NK. Quadratus lumborum block versus transversus abdominis plane block in patients undergoing total abdominal hysterectomy: A randomised prospective controlled trial. Anesth Essays Res. 2018;12(3):742-747. https://doi.org/10.4103/aer.aer_108_18

24. Kumar GD, Gnanasekar N, Kurhekar P and Prasad TK. A comparative study of transversus abdominis plane block versus quadratus lumborum block for postoperative analgesia following lower abdominal surgeries: A prospective double blinded study. Anesth Essays Res. 2018;12(4):919-923. https://doi.org/10.4103/aer.aer_108_18

\section{Authors Contribution:}

MSM - Concept and design of the study, prepared first draft of manuscript, statistically analyzed, and interpreted; SA - Interpreted the results, reviewed the literature, and manuscript preparation; RN - Concept coordination, review of literature, and manuscript preparation; $\mathbf{A H}$ - Concept coordination and revision of manuscript.

Work attributed to:

Lal Ded Hospital, Government Medical College, Srinagar

Orcid ID:

Mohamad Sadiq Malla - (D) https://orcid.org/0000-0003-2189-6320

Sameena Ashraf - (1) https://orcid.org/0000-0002-6494-6896

Rayees Najib - (i) https://orcid.org/0000-0002-1656-2556

Abdul Hakeem - (i) https://orcid.org/0000-0003-1870-3399

Source of Funding: Nil, Conflict of Interest: None declared. 